\title{
The contribution of theory and experience to generic meaning-making: A reflection on participatory system dynamics modelling
}

Short title: The contribution of theory and experience to generic meaning-making

\author{
Nici Zimmermann \\ UCL Institute for Environmental Design and Engineering \\ University College London \\ Gower Street \\ London WC1E 6BT, UK \\ +44(0)2031085951 \\ n.zimmermann@ucl.ac.uk
}

\begin{abstract}
Published as:
Zimmermann, Nici (2017). "The Contribution of Theory and Experience to Generic Meaning-making: A Reflection on Participatory System Dynamics Modelling." Systems Research and Behavioral Science 34(4): 489-493. http://doi.org/10.1002/sres. 2471
\end{abstract}

\section{INTRODUCTION}

Research aims at producing generic insights, transferable across different contexts. In other words, it aims at producing insights at a higher level that can be re-applied and therefore have broader value. The paper by Ulli-Beer et al. (2017) examines how participatory modelling can create generic insights beyond a specific case. Their ambitious inquiry describes a process for generating generic knowledge among a diverse group of stakeholders who possess rich experience.

This poses questions: What is the role of experience? How do participants acquire generic knowledge? What is the contribution of participatory system dynamics modelling in the process of acquiring generic knowledge?

This commentary investigates how theory and experience contribute to generic meaning-making in participatory system dynamics processes. It uses social theories on insight and learning as overarching perspectives for exploring Ulli-Beer et al.'s generic participatory modelling process framework, to theoretically ground their framework and to understand how participants develop generic knowledge. I will proceed by, firstly, investigating the steps of Ulli-Beer et al.'s generic participatory modelling process framework and dividing the framework into three elements: a theoretical perspective, modelling and participatory work. Secondly, I will examine relationships between generic knowledge and the experiential knowledge that participants bring to the workshop and I will reflect on what it means to introduce a theoretical perspective. Thirdly, I will investigate how this relates to the creation of meaning in group processes, and finally, I will summarise and conclude what this implies for the system dynamics process. 


\section{THEORETICAL PERSPECTIVE, MODELLING AND PARTICIPATORY WORK}

Ulli-Beer et al. (2017) develop a generic participatory modelling process framework that combines participatory work with the traditional research process. Their framework can be divided into the introduction of a theoretical perspective, modelling and participatory work. Their process framework enhances applied work with a theoretical perspective and thus complements it with the steps of

(1) defining a problem,

(2) selecting an adequate theoretical perspective and

(3) joining the real-world problem and the theoretical perspective in a phenomenon of interest to be addressed.

Their process also includes modelling through steps of

(4) mapping theory-based conceptual models and

(5) elaborating a generic simulation model.

Similarly, their process enhances the traditional research process with participatory work in the steps of

(6) adapting the model to a specific case and

(7) conducting a case-specific analysis.

All three elements, that is, a theoretical perspective, modelling and the participatory work, come together in the final step of

(8) transforming participants' understanding from the case-related to the generic level.

I will investigate the contribution of a theoretical perspective to participatory work, starting with the relation between experiential and generic knowledge and continuing with participatory meaning-making processes.

Ulli-Beer et al.'s process framework for generating generic insights in many ways corresponds to what Forrester envisioned to be the ideal system dynamics process:

"In addition, if the best industrial dynamics practice is followed, one will usually build generalized models of a phenomenon before he specializes the model to a particular situation. The general model should predict the circumstances under which a particular mode of behavior will be found in the real system." (Forrester, 1968, p. 607)

Ulli-Beer et al. (2017) relate this process of building generic models to participatory research and the co-generation of knowledge with stakeholders. Among the many roles theory can play in research (Boer et al., 2015), they investigate its role for producing further generic knowledge and for increasing the generality of participants understanding of a specific problem, outlined in steps (2) and (3) of their framework. They provide a top-down approach to theorising by already delivering to their stakeholders a middle range theory (Lane, 2000; Merton, 1968) from which generic structures will be developed. This middle range theory serves as the lens through which participants view their specific case.

Mead's $(1925 ; 1934)$ theory of speech and learning in combination with Lonergan's (1958) process theory of gaining insight will help understand how Ulli-Beer et al.'s framework works. It will provide the theory used for comprehending how the generic participatory modelling framework with its use of a theoretical perspective affects 
participants (see also Black, Greer, \& Zimmermann, 2014; Zimmermann, Black, Shrubsole, \& Davies, 2015). Lonergan's theory will help recognise the process of how people come to know something and what this means for how they utilise the theoretical perspective provided to them.

\section{EXPERIENTIAL AND GENERIC KNOWLEDGE}

Lonergan (1958) emphasises that a teacher cannot make a pupil understand, but can systematise and present content in suggestive ways. Ulli-Beer et al.'s theoretical perspective presented to workshop participants serves as a suggestive lens for how to view and understand further content. It gives participants the means to judge whether this content makes sense (Lonergan, 1958). But Lonergan emphasises that any generic or theoretical understanding needs to connect to experience. The participants' rich experiential knowledge is valuable because experience is the material for insights (Lonergan, 1958; Tekippe, 1996). It is central to the creation of meaning (Mead, 1934). People have to relate new knowledge to their experience, they have appropriate it and make it their own to use it.

“To appropriate a truth is to make it one's own." (Lonergan, 1958, p. 558)

This means, the new knowledge needs to make sense in relation to past accumulated experiences. Knowledge derives from experience, but this process is shaped by accumulated knowledge, as it provides meaning, insights and judgment.

While Lonergan regards this judgment process to be rather objective (Roscoe, 2004), I propose it is subjective; 'coloured' by the judge's cultural, paradigmatic and individual embeddedness. Here, presenting the participants with the theoretical perspective becomes useful because it can change the individual 'colouring', i.e. the accumulated knowledge used to understand, and it can prompt the desired generic understanding. It becomes the appropriated basis from which judgment occurs.

\section{MEANING-MAKING}

Mead's $(1925 ; 1934)$ theory of speech and learning in combination with Lonergan's process of gaining insight will provide further theory used for understanding how the generic participatory modelling framework affects participants (see again Black et al., 2014; Zimmermann et al., 2015). Mead's theory helps recognising how a midrange theory serves as a lens for a specific case, how it supports the participatory process and the creation of shared meaning.

Importantly, this lens not only provides participants with the way how they view their case and knowledge, but also how they phrase it. Mead postulates that individuals learn through a reciprocal process of gesturing, involving also visual and vocal gestures. A gesture is an individual's expression that conveys a meaning. During a participatory workshop, facilitators and participants gesture all the time through what they say and display. Gestures are usually anchored in the participants' subjective experience (Gallagher, 2012, referring to Mead, 1904), but while they relate to individual experience and experiential knowledge, gesturing is a reciprocal process, it requires a context, i.e. a community for exchange. Individuals coordinate within a group through evolving relations of gesturers and addressees (Mead, 1934, pp. 179, 323), and through some of these visual and vocal gestures the generic content (the socio-technical transitions framework in this specific case) can be brought in. As individuals derive 
knowledge from others' feedback, participation creates a continuous feedback process through which the participants start to understand the meaning of their own and others' gestures (Gillespie, 2005). This triggers an alignment process by which the participants start to generate shared generic meaning through the feedback they receive from others. Lonergan, too, emphasises the discursive nature of knowing, regarding "human knowledge as not intuitive but discursive" (Lonergan, 1996, p. 265; Tekippe, 1980). This discourse requires generic concepts for interchange. The concepts frame the evolving understanding and evolve themselves. The theoretical framework serves as the concept, i.e. as the lens through which participants begin to re-interpret their rich experiential knowledge about the case. Communication and collaboration in participatory sessions transform the learning process (Lonergan, 1958), corresponding to Voinov and Bousquet's (2010) notion of decisions being by-products of shared learning experiences in model-building processes.

Although Ulli-Beer et al. do not refer to Lonergan (1958) and Mead (1934), the generic participatory modelling process framework corresponds to their theories by providing participants with the concepts through which they observe the case and re-interpret their knowledge about it. System dynamics provides the mechanisms on which observed behaviours depend. As a method, it is naturally prone to providing generic mechanisms that apply to a class of systems, and the participatory work on a theoretical perspective can help participants iteratively express or 'gesture' more generic relationships and develop generic meaning.

\section{CONCLUSION}

This commentary investigated how theory and experience contribute to generic meaning-making in participatory system dynamics processes. It used Lonergan's and Mead's theories of insight and learning as the overarching perspectives for understanding Ulli-Beer et al.'s generic participatory modelling process framework, to further theoretically ground the framework and to understand how participants derive generic insights. But what is this useful for? Looking at the process framework through the lens of the Lonergan's and Mead's theories helps us understand why the process framework can work and how it can be used. The preceding sub-chapters outlined why it can work. In summary, we learned that presenting participants with a theoretical perspective can be regarded a process of gesturing that enables the participants to frame their experiences through the generalisations learned in these gestures. It helps understand how participants acquire new information. This is necessary to know if they are to acquire a theoretical perspective, for example. Importantly, they need to be able to relate the theoretical perspective to what they already know, as theoretical understanding needs to connect to experience (Lonergan, 1958). This may create a chicken and egg problem because experience and abstracted theory mutually reinforce each other and a minimum foundation needs to be in place for the gesturing process to bear fruit. The participatory process may serve as a catalyst. Thus these social theories help us recognise how the mutual exchange between participants (and facilitators) relates to developing insights and shared meaning.

This leads us to the question of how Ulli-Beer et al.'s generic participatory modelling process framework and the theoretical concepts presented here can be used, which is a question for much future research. At this point, however, we can already indicate that it will be useful to generate new scripts aiming at introducing theoretical perspectives and 
to adapt existing system dynamics scripts more closely to the social theories of how people develop insights and shared meaning. The theories help target participatory sessions to how people acquire new information. The process framework can serve as a catalyst for engaging participants with generic concepts. However, the participants need to be able to relate the suggested theoretical concepts to their own experience in order for the acquisition of a theoretical perspective to catalyse more generic insights. Participatory workshops work extremely well for generating such insights because participants make meaning though the mutual exchange of ideas and can iteratively align the generic concepts, but also the variety of experiences that reside in the group.

In addition, the theoretical reflection on Ulli-Beer et al.'s framework represents a further step to addressing the missing underlying social theory and philosophy of science of (participatory) system dynamics. Such work is rare (Lane, 2000), still. Previous exceptions addressing the link between system dynamics and social theory include, for example, clarifications of the integrative position of system dynamics with objectivist and interpretivist science, structure and agency (Lane, 1999; 2000; 2001a; 2001b), relativist philosophical considerations of model validation (Barlas \& Carpenter, 1990) or the use of boundary concepts for better utilising visual representations in participatory modelling (Black, 2013; Black \& Andersen, 2012). Such theory and philosophy of science is necessary to generate insights into how (participatory) system dynamics practices relate to other research, what we come to know through system dynamics models and modelling, what impacts it has and how these impacts come about. 


\section{REFERENCES}

Barlas, Y., \& Carpenter, S. 1990. Philosophical roots of model validation: Two paradigms. System Dynamics Review 6(2): 148-166.

Black, L. J. 2013. When visuals are boundary objects in system dynamics work. System Dynamics Review 29(2): 70-86.

Black, L. J., \& Andersen, D. F. 2012. Using Visual Representations as Boundary Objects to Resolve Conflict in Collaborative Model-Building Approaches. Systems Research and Behavioral Science 29(2): 194-208.

Black, L. J., Greer, D. R., \& Zimmermann, N. S. 2014. Constructing Joint Action in Transdisciplinary Research. Paper presented at the 2014 EGOS Colloquium. Rotterdam: European Group for Organizational Studies.

Boer, H., Holweg, M., Kilduff, M., Pagell, M., Schmenner, R., \& Voss, C. 2015. Making a meaningful contribution to theory. International Journal of Operations \& Production Management 35(9): 1231-1252.

Forrester, J. W. 1968. Industrial Dynamics-A Response to Ansoff and Slevin. Management Science 14(9): 601-618.

Gallagher, T. J. 2012. G.H. Mead's Understanding of the Nature of Speech in the Light of Contemporary Research. Journal for the Theory of Social Behaviour 42(1): 4062.

Gillespie, A. 2005. G.H. Mead: Theorist of the Social Act. Journal for the Theory of Social Behaviour 35(1): 19-39.

Lane, D. C. 1999. Social theory and system dynamics practice. European Journal of Operational Research 113(3): 501-527.

Lane, D. C. 2000. Should System Dynamics be Described as a 'Hard' or 'Deterministic' Systems Approach? Systems Research and Behavioral Science 17(1): 3-22.

Lane, D. C. 2001a. Rerum cognoscere causas: Part I-How do the ideas of system dynamics relate to traditional social theories and the voluntarism/determinism debate? System Dynamics Review 17(2): 97-118.

Lane, D. C. 2001b. Rerum cognoscere causas: Part II-Opportunities generated by the agency/structure debate and suggestions for clarifying the social theoretic position of system dynamics. System Dynamics Review 17(4): 293-309.

Lonergan, B. J. F. 1958. Insight: A study of Human Understanding. New York, NY: Philosophical Library.

Lonergan, B. J. F. 1996. Insight: Revisited. In W. F. J. Ryan, \& B. J. Tyrrell (Eds.), A Second Collection: Papers. University Of Toronto Press: Toronto: 263-278.

Mead, G. H. 1904. The relations of psychology and philology. Psychological bulletin 1(11): 375-391.

Mead, G. H. 1925. The Genesis of the Self and Social Control. International Journal of Ethics 35(3): 251-277.

Mead, G. H. 1934. Mind, Self, \& Society: From the Standpoint of a Social Behaviorist. Chicago: University of Chicago Press.

Merton, R. K. 1968. Social Theory and Social Structure: Free Press.

Roscoe, K. 2004. Lonergan's Theory of Cognition, Constructivism and Science Education. Science \& Education 13(6): 541-551.

Tekippe, T. J. 1980. An Investigation of the Balance Between Conceptual and Primordial Knowing in Major Figures of the Western Philosophical Tradition. Tulane University, ProQuest Dissertations. 
Tekippe, T. J. 1996. What is Lonergan Up to in Insight?: A Primer. Collegeville, MN: Liturgical Press.

Ulli-Beer, S., Kubli, M., Zapata, J., Wurzinger, M., Musiolik, J., \& Furrer, B. 2017. Participative modelling of socio-technical transitions: Why and how should we look beyond the case specific energy transition challenge? Systems Research and Behavioral Science 34.

Zimmermann, N., Black, L., Shrubsole, C., \& Davies, M. 2015. Meaning-making in the process of participatory system dynamics research. In Proceedings of the $33 \mathrm{rd}$ International Conference of the System Dynamics Society. Cambridge, MA. 